Journal of Transport and Land Use 1:2 (Fall 2008) pp. 5-22

Available at http://jtlu.org

\title{
JTLU
}

\section{Accessibility: Long-term perspectives}

\author{
Kay Axhausen \\ Institute for Transport Planning and Systems, \\ Swiss Federal Institute of Technology Zürich
}

\begin{abstract}
Improved accessibility and its correlate lower generalized cost of contact, travel and transport have been sought by dynamic human societies for their economic and social benefits throughout recorded history. The paper will reflect about this process at a number of different spatial and temporal scales based on a conceptual model. Looking back at European history, it will trace the interaction between Christaller's logic of local market areas and the idea of (low contact cost) network cities. Focusing on Switzerland since 1950 it will show how network investment changed the relative distribution of population and employment and how this interacted with changes in the preferences of the travelers. Using a recent snapshot of how a substantial sample of Swiss maintain their social networks over often very large areas, it will try to answer the question of what will happen in the future, if the current trend of ever lower costs of contact persists.
\end{abstract}

Keywords: Accessibility; Policy; Network growth; Social network geography.

\section{Introduction}

Transport policy and planning are increasingly concerned with improving or optimizing accessibility, a term often mentioned in the abstract but equally often left undefined or unmeasured. This paper does not reflect on why policy has shifted in this direction, nor on the political economy of the term and the intentions behind it; its aims are much more limited. In three brief sections, the paper sketches three issues that relate to the discussion of accessibility and provide some hopefully useful background to these ongoing policy shifts. The first section discusses two logics of organizing cities across space: Christaller's (1933) logic of locally self-sufficient production and the logic of long-distance trade. This leads to a conceptual model of accessibility production in modern societies, where accessibility is driven by the need to provide increasing incomes for burgeoning populations. The second section illustrates this accessibility

aaxhausen@ivt.baug.ethz.ch

Copyright 2008 Kay Axhausen.

Licensed under the Creative Commons Attribution - NonCommercial License 3.0. 
production with a review of the Swiss experience during the last 150 years. It also shows that this policy has started to run its course, as the marginal gains of further accessibility increases are decreasing. Shrinking Switzerland further is becoming an increasingly costly way of supporting economic growth. The final section shows how travellers have adjusted their social lives to these new realities. It reports the results of a survey of the globalisation of social contacts and networks. The ego-centric networks of the Zürich respondents reflect the fallen cost of travel and contact and include both local and (inter)-national friends. Travellers have reconstructed the spatial structure of their social capital. The paper closes with some ideas of what this new reality means to transport policy and where future research challenges lie.

\section{Undifferentiated plane and network city}

In Christaller's (1933) classic model of city location under conditions of locally selfsufficient (autarkic) production, cities of different rank are positioned at the appropriate points of maximum accessibility. The resulting pattern of hexagonal market areas has always been disrupted by the establishment of cities and settlements motivated by three alternative priorities: governance or rule; consumption; and long distance trade. Historically, cities founded for extractive rule and for sheer (luxury) consumption have never grown large. In contrast, cities established for long-distance trade were able to grow larger than autarkic "production" cities. Historic examples of government cities and associated (luxury) consumption are Jerusalem, Rome, Kyoto, Edo, Peking, and Versailles; note that only the capitals of empires grew to any size, as they were able to commandeer the required food supplies and resources. Typically, cities associated with local rule followed the system of autarkic production. Only with state formation were the higher levels of government able to free themselves of these constraints. Still, path dependency normally led to the adoption of previously established locations.

The system of cities engendered by trade and its associated value-added production is controlled by a different logic than the hexagonal system of autarkic production, which covers a whole territory exhaustively. Trading cities locate where the technology of the time requires a change in the mode of transport, in particular from a faster, more efficient and cheaper mode to a less efficient mode: harbors intermediating between ocean shipping and rivers; between lakes and rivers; between rivers and carts; or between carts and sleds (e.g. Chur at the bottom of the Swiss alpine passes Julier, Abula, Majola, Septimer, St. Bernhard, Splügen and Lukmanier). Later, in addition, government privileges of enforced bulk-braking achieved the same effect, as the examples of Nürnberg, Leipzig, and Frankfurt in Germany attest. For most of history, water-borne vessels were faster, had larger carrying capacities and were cheaper, favoring them wherever a navigable watercourse was available, which in a time before river regulation was not as often as we would think today. Trading cities were able to escape the constraints 
of their cart-accessed hinterlands and to grow as far as their water-accessible hinterlands would allow. The geography of these break points follows the patterns of nature, overlaying and transforming the logic of the hexagons, as the trading cities were normally the stronger parties. Historically, the boomtowns and bust-towns of resource extraction (e.g. mining of ores and of salt) added further randomness to the overall pattern. While the logic of the trading cities does not follow the logic of exhaustive rule and autarkic production, trading cities depend on the settlements established under the autarkic system for custom.

Historically, trade goods tended to have high value densities to justify their cost of transport; alternatively, trade goods such as cattle, sheep, horses, and slaves were forced to walk themselves (See McCormik, 2001; Bonser, 1970). Such luxury demand was driven by the desires of local elites for prestige and differentiation, and was therefore relatively price-insensitive. Under those conditions, therefore, investment in accessibility was mostly driven by military considerations, as the Roman road system shows. The demand of concentrated military populations supported a certain amount of long distance trade in everyday goods, as is well attested for the Roman empire and its legions ${ }^{1}$

Investment in accessibility for trade in everyday goods and services becomes an issue when a mass demand supported by growing populations begins to materialise and when the producers want to take advantage of economies of scale. This begins when, for the given technology, any local population surplus can no longer be absorbed through further intensification of agriculture, i.e. by adding layers to the central place hierarchy $\mathrm{2}^{2}$, or by converting hitherto marginal land (forest, swamp, heath, mountain valleys) into (albeit less productive) farmed land, or finally by emigration. See Clark (2007) for a thorough discussion of the Malthusian regime before the industrial revolution, but which ignores these processes before 1800 .

It is unclear when the logic of the three-way interdependency-the virtuous cycle that ties together growth in income, achievement of economies of scale and scope, and increase in market area via lowering of the generalized costs of travel—was first fully understoo ${ }^{3}$ (See below for a discussion of this virtuous cycle). By the late eighteenth century, most of the individual ideas needed to understand the cycle had been formulated (Smith 1776; Ricardo 1817). European states had started to behave as if they had understood this earlier (de Vries and Van der Woude 1997; Spufford 2002), as evidenced by Florentine road investment in the fourteenth and fifteenth centuries,

\footnotetext{
${ }^{1}$ Feeding Rome and Constantinople was a different matter, which required substantial fleets and even larger tax incomes.

${ }^{2}$ A good example is the Japanese adoption of wet-paddy rice cultivation in the Edo period, including the development of a steady fertilizer supply from urban areas (night soil)

3 Generalised costs are the weighted sum of the resources consumed for a movement: money and time. The weights reflect also the comfort, safety and reliability of the movement.
} 
Dutch canal investment from the seventeenth century onwards, and British canal and turnpike investment in the eighteenth.. In the nineteenth century, programmes of canal, road and railway investment became a core activity of the new nation-states, as they aimed to mobilise their populations and their economies. In the liberal climate of that time, the nation-states fully understood that lowering the cost of travel threatens local monopolies as effectively as the official abolition of restrictive guild practises, or of local bridge tolls and imposts (See Figure 1 for the Swiss conditions in 1825).

The anxiety caused by the anticipated loss of secure local monopoly production is even today a central reason for local resistance to improved accessibility. Still, most nation-states adopted policies to destroy those monopolies within their national borders, as national governments knew that such monopolies are likely to hinder innovation and increase prices, and thereby suppress demand. Nevertheless, the long and torturous history of the EU internal market or of worldwide trade liberalisation shows how reluctant nation-states are to adopt these policies at international scales even today.

Although it is an important issue today, there was little concern in the nineteenth century over who would reap the benefits of increased accessibility. In principle, it is impossible to say which end of a new connection will gain the most, as no one can predict with certainty which firm will be the first to invest or to provide an innovative good or service that can only flourish given the new market size. It is commonly assumed that the side relatively stronger in terms of population, capital, or innovation ability is more likely to win in those domains for which its resource endowments favor it; the other end will gain in those areas for which it has the relative advantage.

Within the framework of the virtuous cycle outlined above, Figure 2 identifies the mechanisms through which the generalised cost of travel are lowered and adds the feedback loop of congestion and unreliability which can temporarily dampen the fall in generalised costs. The increased incomes are used by individuals and governments to build more and faster slots, i.e. physical infrastructure and management systems, which provide the time-space paths for travellers and their vehicles. They also acquire larger, more comfortable and faster vehicles — trading up-front capital expenditures for lower generalised costs of trave 5 .

In addition, increases in the level of out-of-home activity are expected, especially through the entry of females into the out-of-home labor market and through an increasing ability to purchase services delivered outside the home (meals in restaurants; holidays; hair cuts; visits to cinemas, theaters, and concerts; childcare; etc.). It is generally assumed that this demand elasticity is small, but this assumption is not backed

\footnotetext{
${ }^{4}$ Seventeenth- and eighteenth-century French road building was still very much guided by military considerations.

${ }^{5}$ Frei (2005) and Raff and Trajtenberg (1985) show how dramatically the quality adjusted prices of cars have dropped since 1900, supporting the increased uptake of car ownership.
} 
Figure 1: Swiss network of lake-side tolling stations in 1825.

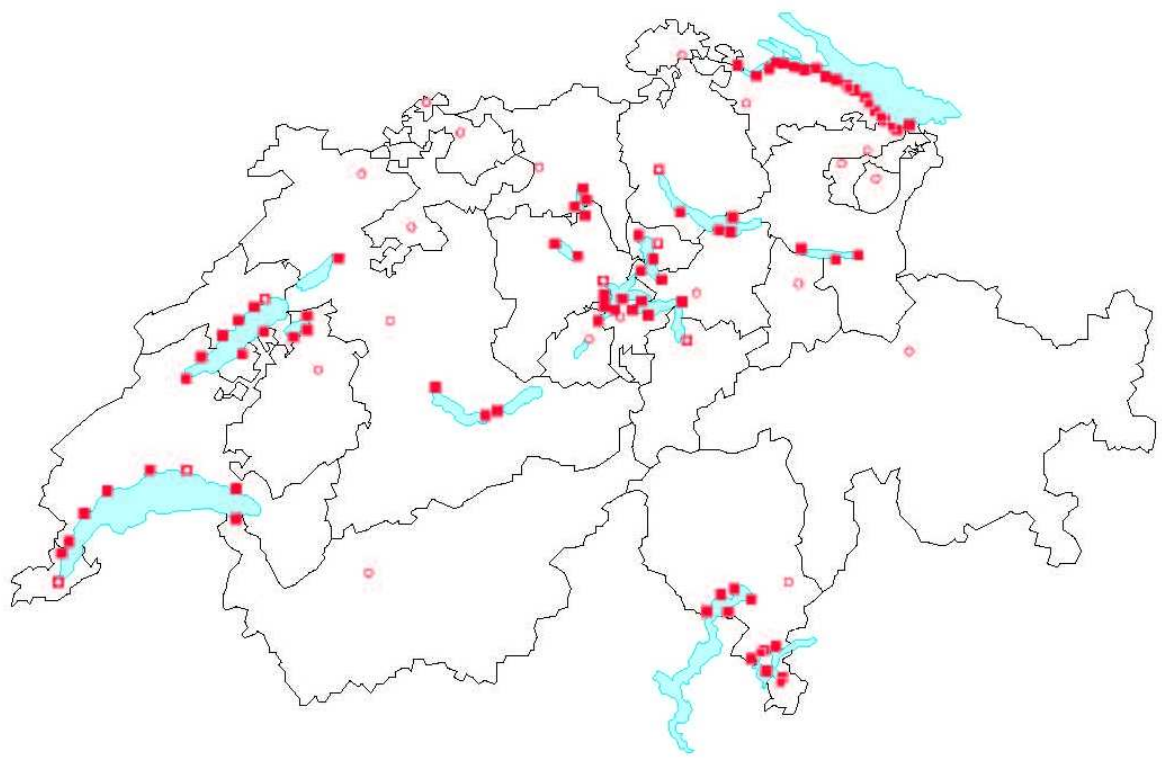

Source: Fritzsche, Frey, Rey and Romer (2001); there was, in addition, a rich network of road and bridge-based toll stations. (Legend: empty squares = cantonal capitals; filled squares $=$ toll stations)

by strong empirical evidence. Stronger empirical evidence is available for income elasticity of the value of travel time savings (see Fosgerau 2005 for review and new results), for which the assumption of a unit elasticity is reasonable. This increasing impatience favors the further expansion of the transport system. The fall in generalised cost is translated into larger market areas, and therefore into increases in person and freight travel. In conjunction with the growth of the vehicle fleet, this increases vehicle travel more than proportionately and leads to congestion as long as the number of slots (or capacity) lags behind current demand. Congestion increases the average cost of travel and, equally importantly, increases the variance in the cost of travel as the system becomes more sensitive to small fluctuations in demand. 
Figure 2: The virtuous cycle of welfare, productivity and market size: A qualitative model.

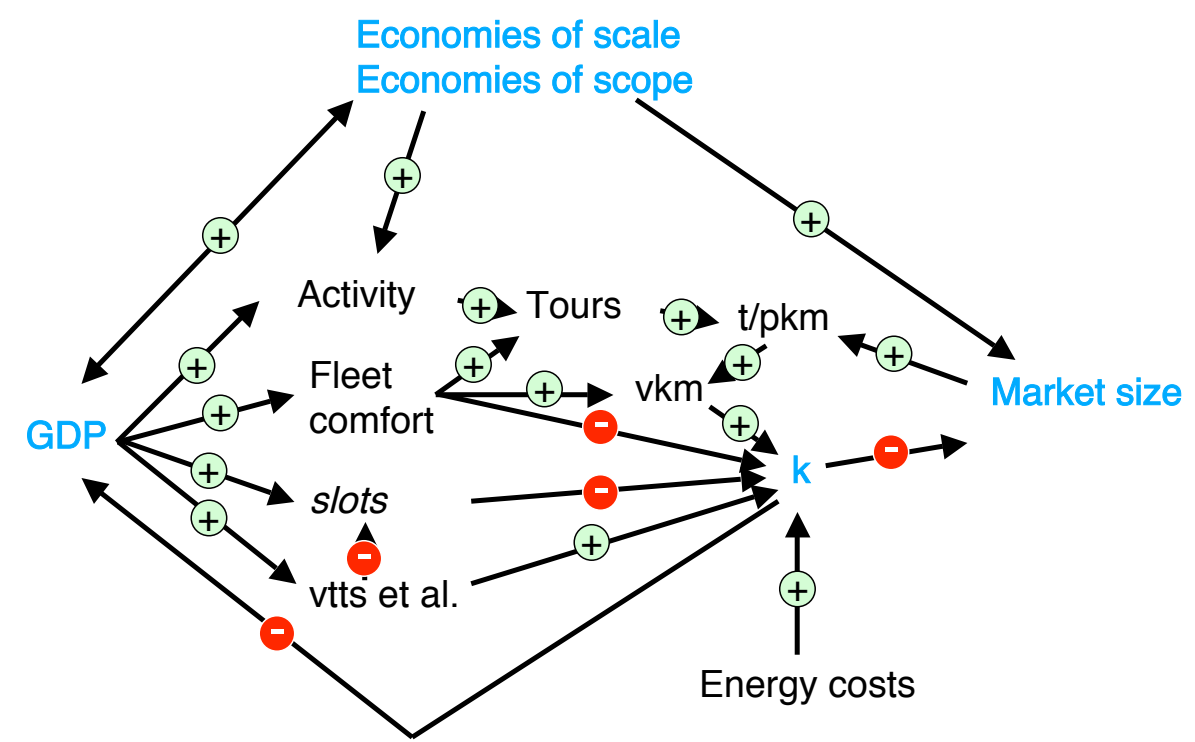

† Elasticity $>0 \quad$ Slots: possibilities to move goods or people

- Elasticity $<0$ For a given infrastructure and commercial and private fleet

$\mathrm{vkm}=$ Vehicle-kilometres travelled; $\mathrm{t} \mathrm{km}=$ ton-kilometres transported; $\mathrm{pkm}=$ Personkilometres travelled

\section{The Shrinking of Switzerland since 1950}

The model sketched above says nothing about the speed and strength of the changes induced by expanded accessibility. Much of the literature has looked at relatively short time periods (10 to 15 years), making it difficult to assess this issue, or to answer the question of whether saturation effects might set in over time (Aschauer 1989; Kesselring, Halbherr and Maggi 1982; or Shirley and Winston 2004 provide a good starting point). A series of research projects (Fröhlich 2008; Tschopp 2007; Axhausen et al. 2008) have analyzed accessibility changes in Switzerland over the last 150 years, giving particular attention to resolving the changes at the level of the roughly 2,900 Swiss local authorities over the last 50 years. Based on assignment-ready network models for road traffic and public transport for each decade since 1950, accessibilities were calculated for each municipality. For the period since 1850 this calculation was performed for the 184 Bezirke or districts, based on less detailed travel time calculations for the 
time before 1950 (Figure 3). See Axhausen, Fröhlich and Tschopp (Forthcoming) for technical details of the network models and the calculations.

Figure 3: Accessibility change since 1850: Box plots of the values of the 184 Bezirke.

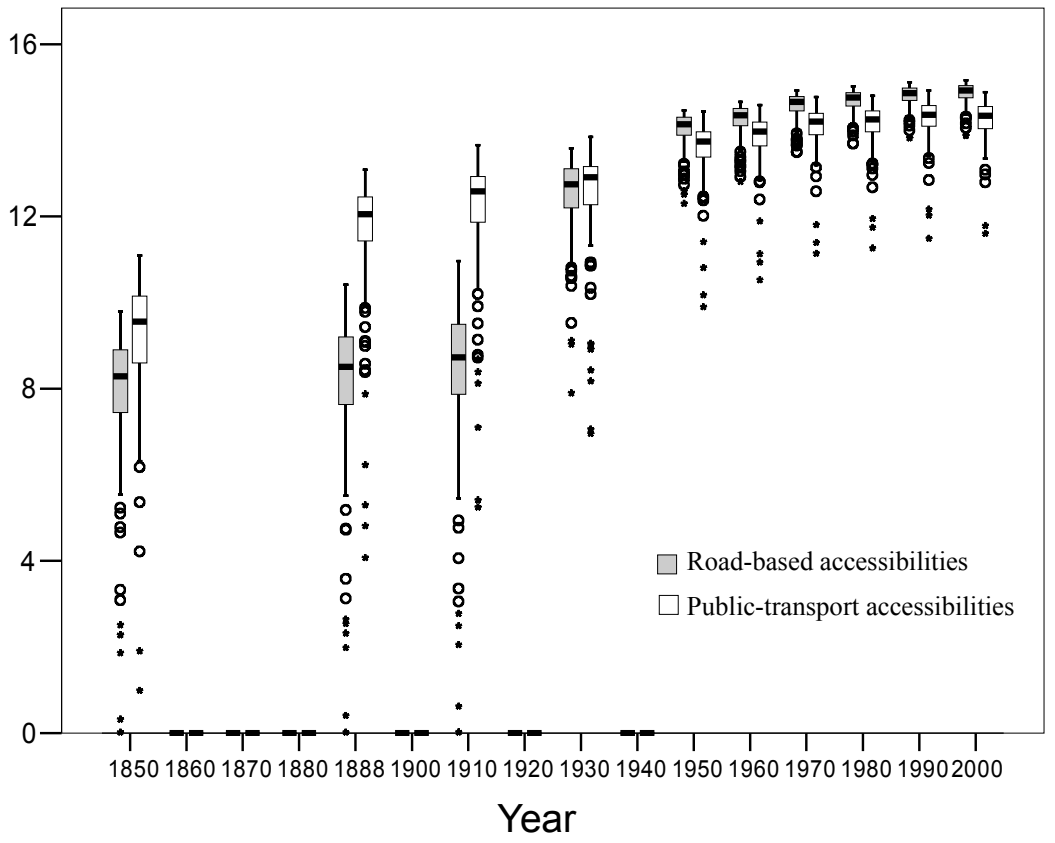

The accessibilities (y-axis) are the log of the sum of the weighted number of residents which can be reached in the other Bezirke by either road or public transport. An exponential weighting function of Bezirk populations with the parameter 0.01 was chosen for the travel times by road and public transport respectively.

The accessibilities only considered the contributions of other districts.

Box plots show the median (thick line), the 1st and 3rd quartile (box) and outliers beyond that inner range (thin line).

In Figure 3, the saturation of the accessibilities is clearly visible in spite of ongoing investment in road capacity and public transport frequencies. The road-based accessibilities overtake the public transport based-ones only in the 1950s, when car-based travel became the default mode for road travel. The improvements in speed of the ever-growing car fleet, supplemented by motorway construction, have maintained this advantage ever since. Public transport in Switzerland has mainly benefited from improved scheduling, as very little new capacity has been built since the Second World War. The impact of the improved frequencies is not included in this figure, which would reduce the differences between the two systems. An intuitive way of visualising 
the changes brought by the ongoing investment is to produce time-scaled maps of the country, as in Figure 4. Here, the distances in the map are proportional to the travel time between any two points. The effective shrinkage of the country is obvious. Roadbased Switzerland has been halved, whereas the reduction factor is somewhat smaller for public-transport-based Switzerland. The differences between different regions are evident in the regionally varying distortion of the $10 \mathrm{~km}$ by $10 \mathrm{~km}$ grids shown in the maps.

Figure 4: Road travel time-scaled maps of Switzerland (same scale for both years).

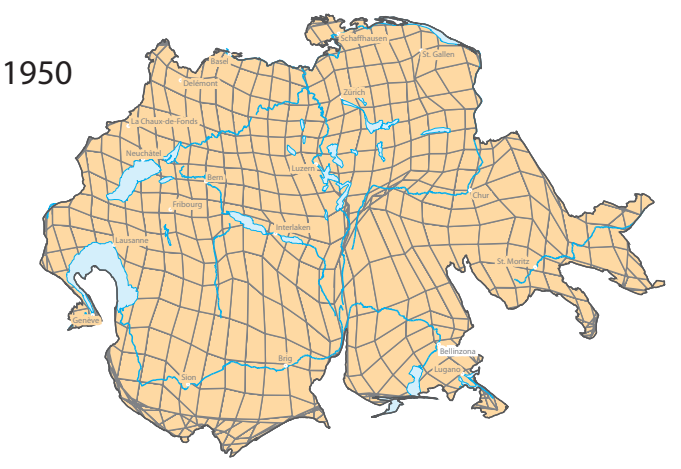

2000

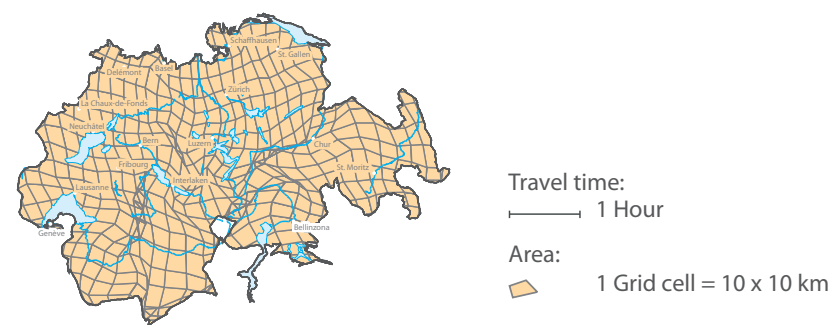

Source: Axhausen, Dolci, Fröhlich, Scherer and Carosio (2008).

The population has adapted to this change, as shown by steady increases in commuting distances (Figure 5), which are being travelled at steadily increasing speeds. Fröhlich, using commuter matrices and associated network models for time since 1970, shows in his thesis that the implied values of travel time savings rise in line with real incomes for public transport users, and rise faster than real income for car users.

Fröhlich also shows that further improvements in overall accessibility, measured 
Figure 5: Swiss commuting distance distributions since 1970.

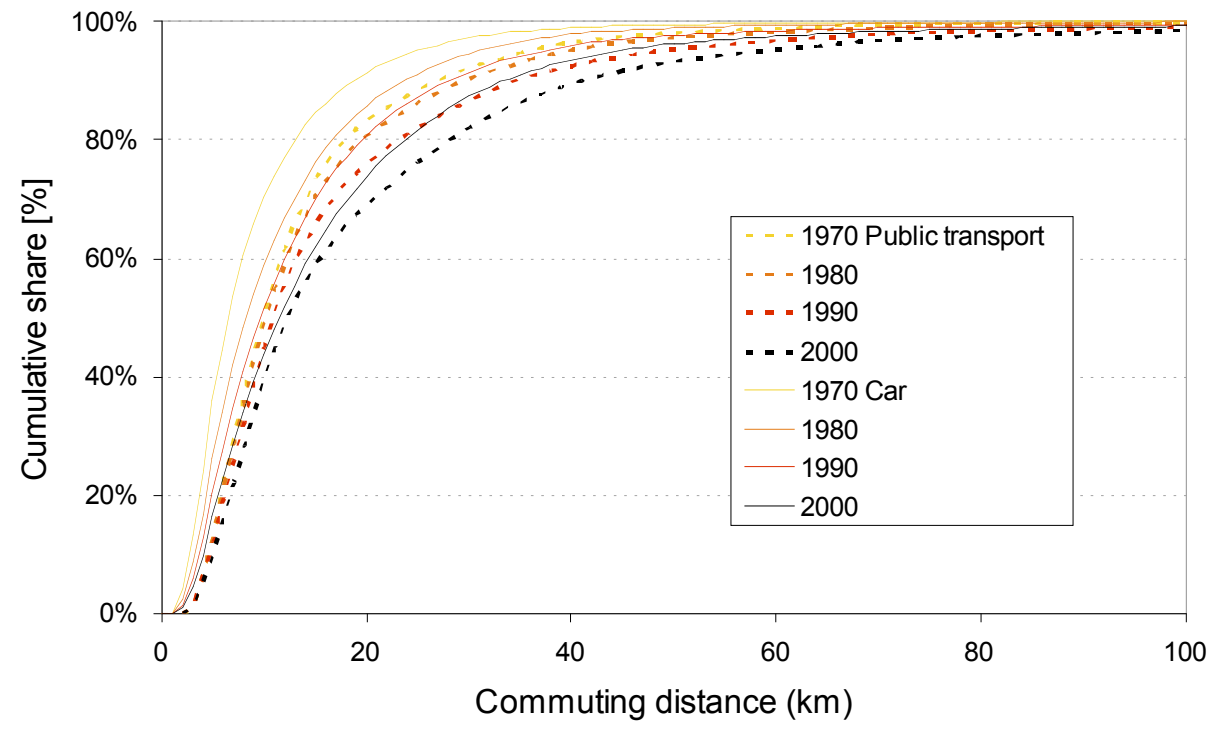

Data: Swiss Census 1970-2000.

with the log sum term of a combined destination and mode choice model for commuting, have decreasing impacts on the willingness to commute. The elasticity of accessibility drops by nearly half between 1970 and 2000. It is reasonable to assume that this saturation is also noticeable in its effect on relative population growth.

Tschopp demonstrates that accessibility change is positively correlated with relative population growth (Table 1). Municipalities that benefitted from accessibility increases grew faster than the national average, even after correcting for employment growth in the municipality. However, this effect is lessening; over the five decades that were compared, the impact becomes smaller for road-based accessibility and the explanatory power of the models decreases. Both trends indicate saturation effects at the national level.

Breaking the results down by canton in a multi-level regression framework Tschopp showed that these saturation effects are most pronounced in those parts of the country which started with relatively high levels of accessibility. In the peripheral cantons, second-tier cities can still benefit strongly from accessibility gains, but more at the expense of the periphery than of the major centres.

In summary, the Swiss case demonstrates how radically the generalised costs of travel have been reduced over time, but also shows the decreasing marginal contributions of further investment in a well-established network. The impacts on residential 
Figure 6: Values of travel time savings (VTTS) for Swiss commuting since 1970.

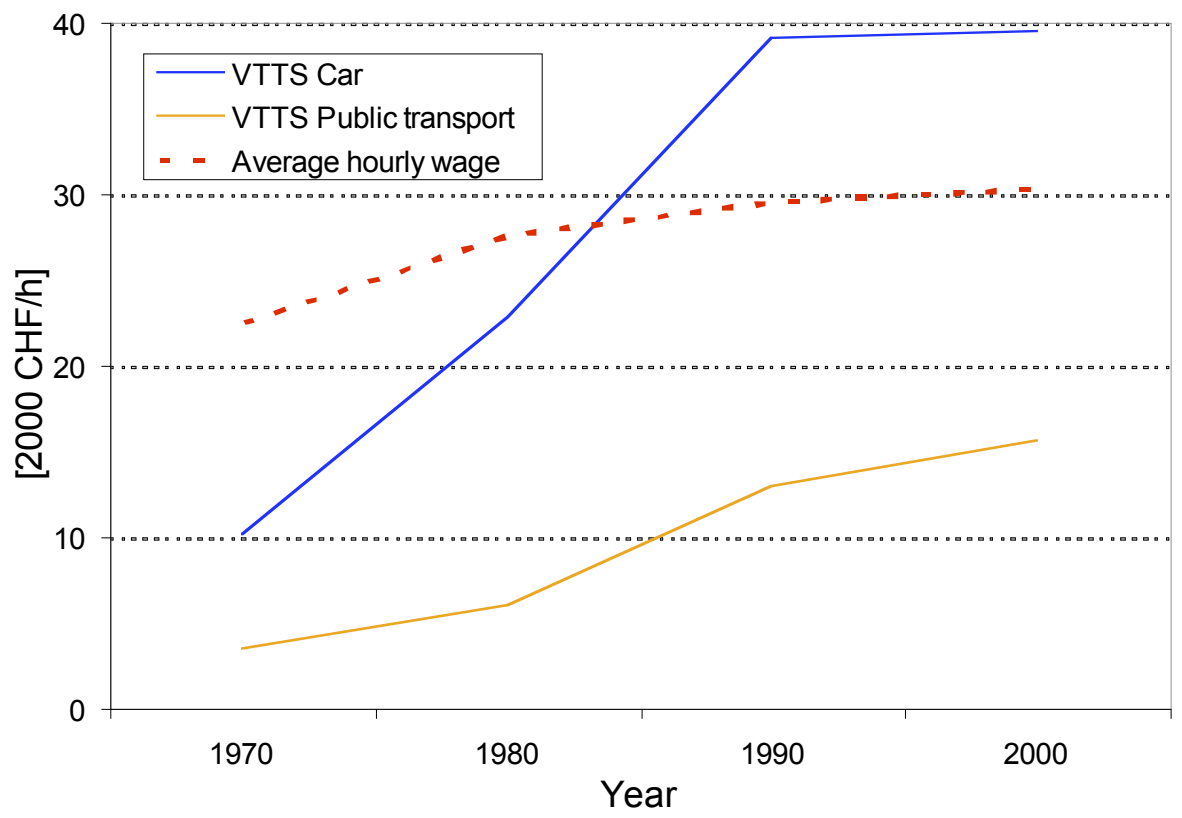

Source: Fröhlich (2008); estimated using census information and the IVT network models.

choice and travel behaviour are also tapering off. While improvements to overall accessibility were able to mobilize the population strongly from the 1950 s to the 1970 s, they have become much less important in the last decade. Away from the core of the country, accessibility change has above-average impacts, but mostly at the expense of the immediate environments of the growth pole.

\section{Friends in a shrunken world}

As space shrinks, the reach of individuals should expand. Leisure travel has been consistently the fastest growing segment of the transport market for some time (see for example http://www.world-tourism.org/facts/menu.html for international tourism). Leisure travel shares of 40 percent of travel and 40 percent of mileage travelled are common in industrialized countries (e.g. Bundesamt für Statistik 2000; Bureau of Transportation Statistics 1995). Leisure travel is, to the largest extent, travel to be with other persons (See Figure 7). It is therefore necessary to establish how those persons 
Table 1: Relative population growth (\% of national average): Parameter estimates of spatial error regression models.

\begin{tabular}{|c|c|c|c|c|c|c|}
\hline \multirow[b]{2}{*}{ Variable } & \multicolumn{2}{|c|}{ 1950-1970 } & \multicolumn{2}{|c|}{ 1970-1980 } & \multicolumn{2}{|c|}{ 1990-2000 } \\
\hline & Param. & $\begin{array}{l}\text { Sig. } \\
\text { level }\end{array}$ & Param. & $\begin{array}{l}\text { Sig. } \\
\text { level }\end{array}$ & Param. & $\begin{array}{l}\text { Sig. } \\
\text { level }\end{array}$ \\
\hline Adj. $R^{2}$ & 0.383 & & 0.715 & & 0.309 & \\
\hline Constant & 0.190 & 0.563 & 0.001 & 0.966 & -0.007 & 0.788 \\
\hline $\begin{array}{l}\text { Employment growth } \\
\text { (2. sector) }\end{array}$ & -0.025 & 0.105 & 0.013 & 0.172 & 0.014 & 0.364 \\
\hline $\begin{array}{l}\text { Employment growth } \\
\text { (3. sector) }\end{array}$ & 0.089 & 0.000 & 0.068 & 0.000 & 0.011 & 0.492 \\
\hline $\begin{array}{l}\text { Change in car-based } \\
\text { accessibility }\end{array}$ & 0.246 & 0.000 & 0.082 & 0.000 & 0.150 & 0.000 \\
\hline $\begin{array}{l}\text { Change in } \\
\text { public-transport-based } \\
\text { accessibility }\end{array}$ & 0.267 & 0.000 & 0.777 & 0.000 & 0.430 & 0.000 \\
\hline Spatial error correlation & 0.555 & 0.000 & 0.464 & 0.000 & 0.412 & 0.000 \\
\hline
\end{tabular}

Source: Tschopp (2007); the weight matrix of the spatial error model includes 8 neighbors, which was shown to be the optimal number; indicating that the immediate vicinity has an impact on the local growth pattern.

are distributed over space, if one wants to explain leisure travel and its further growth. Are friends, relatives and contacts mostly local or are they now spread across larger areas? The shrunken world shown above would suggest the latter, as the former would imply trip rate increases which have not been observed. While further accessibility gains might not shift the residential population anymore, they might continue to have large impacts on the geographies of social networks, particularly as the generalised costs of long-distance travel and communication continue to fall quite quickly due to the availability of low-cost (intercontinental) airline service, zero- or marginal-cost voiceover-Internet-protocol telephony, commodity pricing of mobile telephony, and zeroor marginal-cost e-mail. These factors should increase the distances and the associated spread of the friendship networks.

Unfortunately, sociologists and geographers have not addressed this issue in their research into social networks and neighboring, as their focus of attention lies elsewhere ${ }^{6}$ Recent surveys have started to fill this gap in our knowledge by measuring the distances between precisely geocoded home locations of respondents and their contacts

\footnotetext{
${ }^{6}$ See Mok and Wellman 2007 and Carrasco 2006 for two recent exceptions.
} 
and by asking about the contact frequencies by main modes of contact (face to face, telephone, texting (SMS) and email7).

Figure 7: Mean number of persons travelling with the respondents of the 2003 Thurgau six-week travel diary survey by type of leisure.

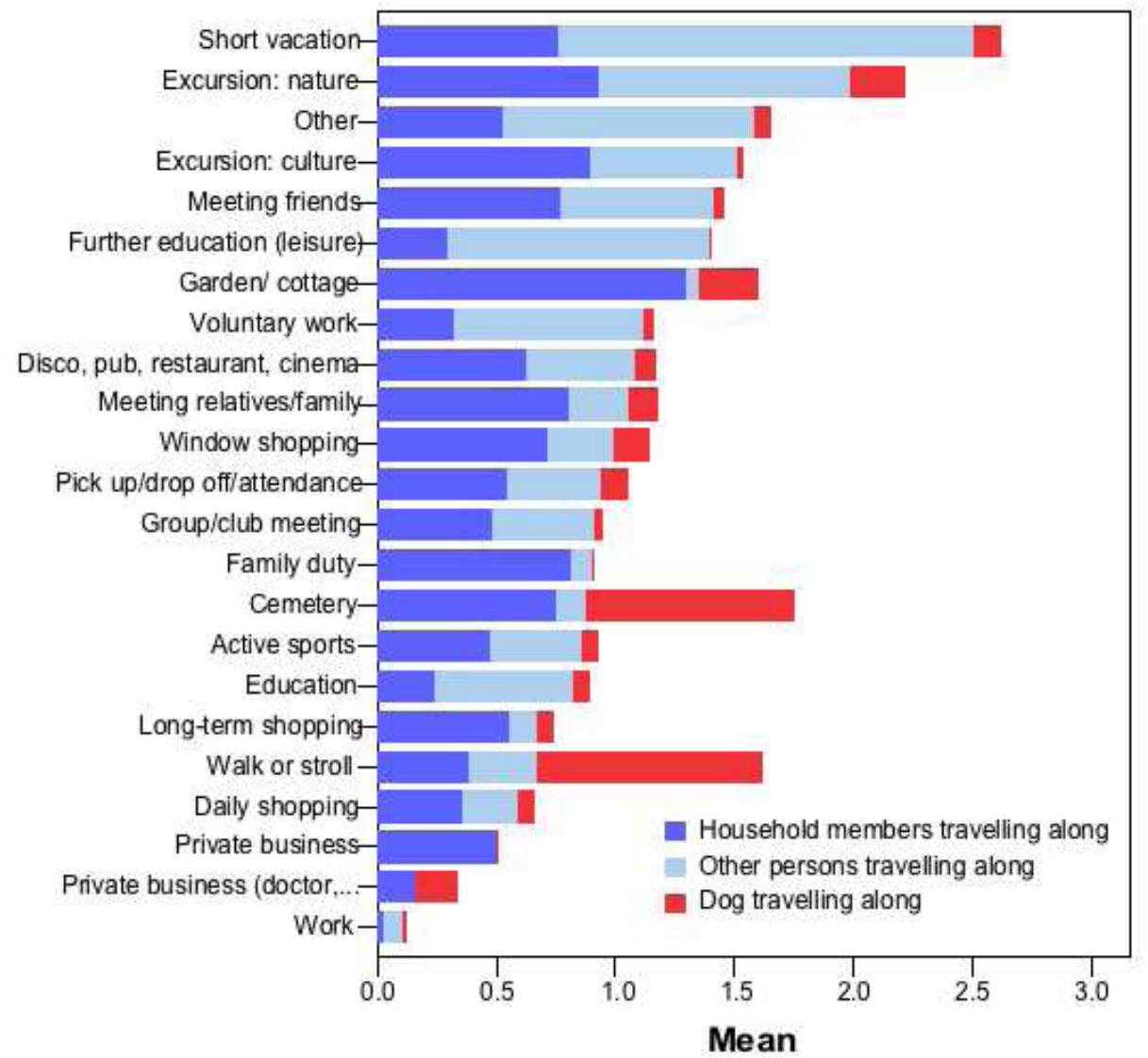

Data: Löchl et al. (2005).

After a series of pre-tests and qualitative interviews, the main survey involved 300 Zürich respondents, who participated in a 60-70 minute face-to-face interview and returned a self-completion questionnaire of about the same duration (247 of these are used in these first analyses). The key items for discussion here were the name generator

${ }^{7}$ Letter writing was omitted as it has become marginal; chat and instant messaging were omitted due to our $a$ priori assumption that it would parallel the patterns of the phone contacts 
and name interpreter questions. Respondents were asked to identify first those people who are emotionally and socially important to them, and second those with whom they spend leisure time; it was assumed that these will also be the respondents' friends. The respondents reported an average of 12 contacts (median 10), for which they indicated the frequency of face-to-face meetings, phone calls, SMS messages and emails.

The key results can be summarised by three graphs. Figure 8 shows the distribution of the distances between the respondents and their contacts. The distances follow an exponential distribution. The median is $9.6 \mathrm{~km}$, but the mean is $325 \mathrm{~km}$. This mixture of local, regional, and international is typical and also was observed in our earlier work.

Figure 8: Great circle distances between the respondents and their contacts.

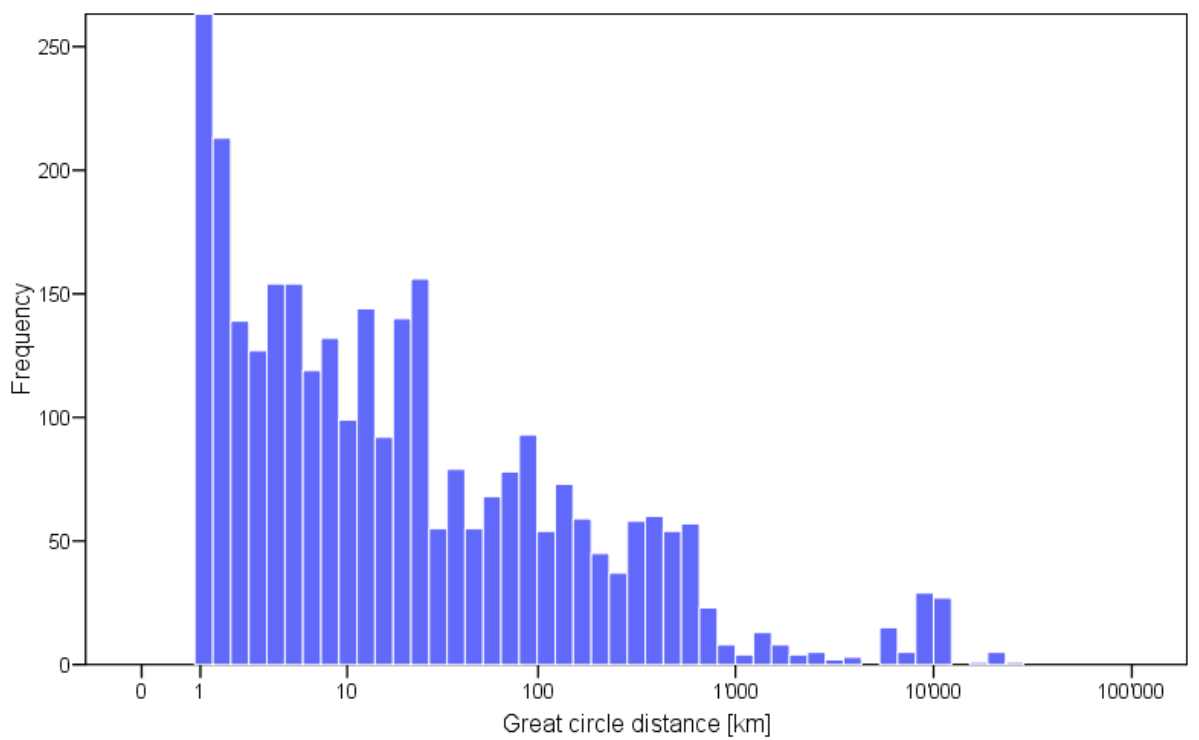

Note: The great circle distance accounts for the spherical shape of earth. Distances between local contacts, i.e. with the same zip codes for the home addresses, were coded as $1 \mathrm{~km}$.

The importance of the mix of the local and non-local is evident in Figure 9, which shows the distribution of the shares of local contacts, here defined as within $2.5 \mathrm{~km}$ from home, among all reported contacts. About six percent of the respondents have only local friends ( 80 percent and more), while the share of those with no local contacts is, at 45 percent, much larger ( 20 percent and less). The bulk has a ratio of about 30 percent, as implied in the share of local distances. Respondents need both for their daily lives. The effort they are willing to accept falls with the frequency of meeting their friends face to face. The rare, once- or twice-yearly meeting involves hundreds of kilometres of travel.

The frequency of face-to-face contacts follows an exponential decay trend (Figure 
Figure 9: Share of respondents with a given share of contacts among all contacts within their residential postal code.

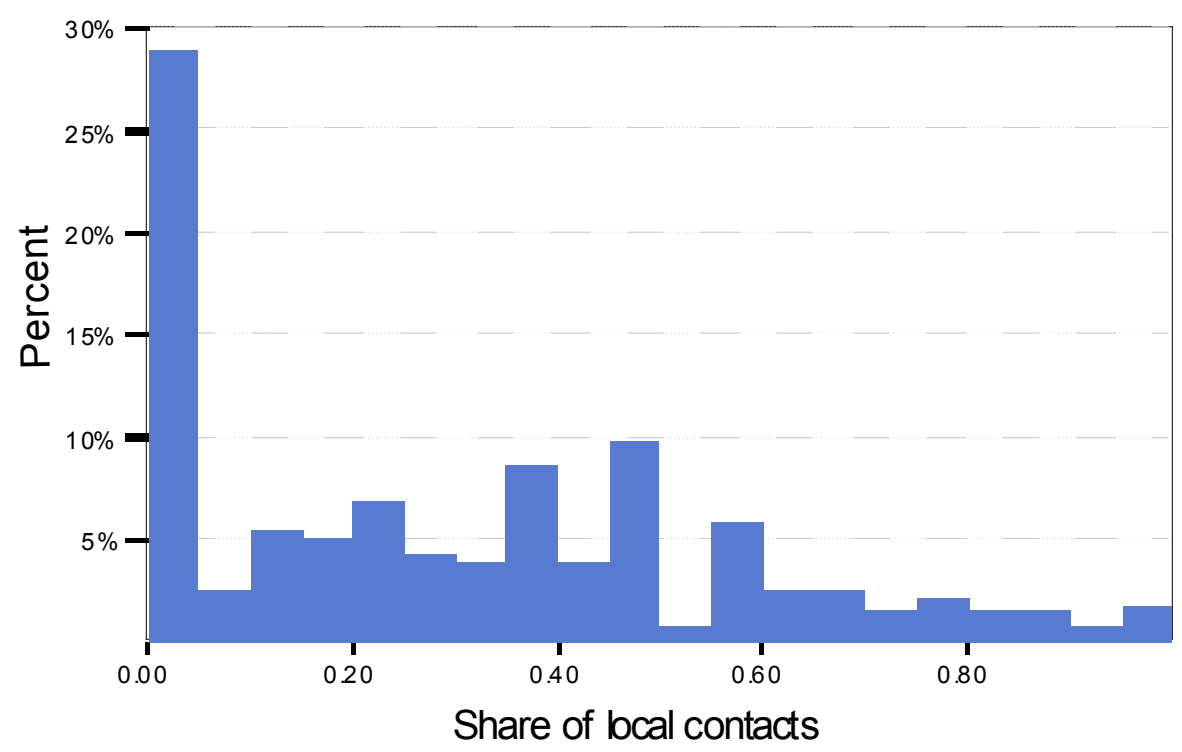

10), as does the frequency of telephone contacts. Asynchronous messages (e-mail and SMS messaging) are independent of distance. The three modes reinforce each other, especially as the asynchronous messages are mostly about the co-ordination of meetings for friends living close to one another. Telephone calls and face-to-face meetings do not replace each other, but complement each other.

In the absence of previous measurements, the rate at which social networks have spread during the last 50 years is unknown. As discussions about a supposed or real lack of neighborly contact are common in the literature after the Second World War, it is reasonable to assume that the process had already started by 1945 (See references in Campbell 1990; Campbell and Lee 1992; Day 2006; and Lloyd 1984). In the absence of low-cost options for air travel and telephone service, it is reasonable to assume that social networks were decidedly more regional than they are today. This implies that generalised cost elasticities were relatively strong in the past, and suggests that further growth is likely in the future.

In summary, today's travellers have chosen to mix local with distant friends. Distance still matters for the frequency of the interactions, but those rare visits involve very 
Figure 10: Average number of annual contacts by distance and mode of contact.

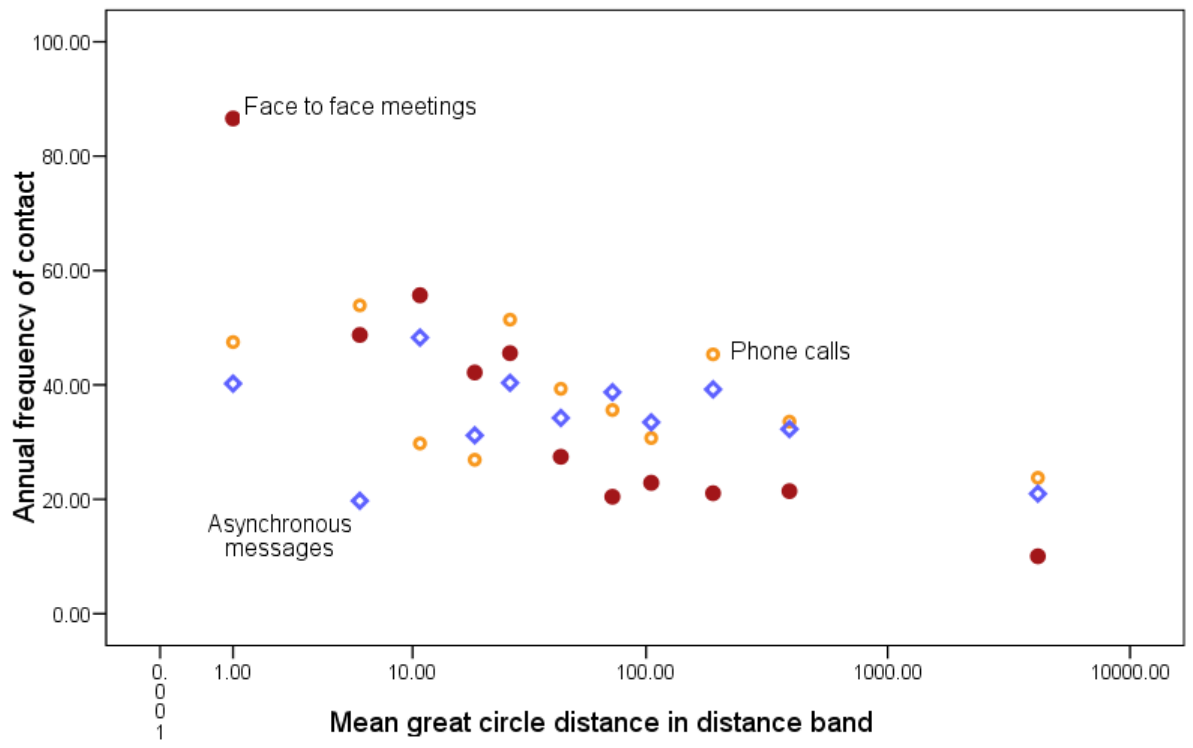

Note: Asynchronous messages include SMS or texting (short message service) and e-mail.

considerable distances and travel times. These patterns have implications for transport policy, as the current levels of social capital are tied to these spatially spread patterns of friendship and contact.

\section{Policy implications: Dimensions of decoupling}

The globalisation of economic and social networks seems set to continue. China, India and other developing countries are investing heavily in lowering the generalised costs of travel and transport inside their borders. Industrialised countries are also pursuing capacity expansion, but not at the same rate as they did in the 1960s and 1970s. Ongoing growth in world trade and tourism is providing the demand which is driving investment in infrastructure and vehicles. At the same time, global warming and the demands of global migration have made societies around the world aware of the constraints imposed by climate change and energy availability. In addition, at the national scale, there is a requirement for regional equity, while the consideration of global equity is increasingly important, as well. Both requirements favor further investment in transport systems. Transport policy, as a component of economic and social policy, has to find ways of meeting a dual challenge: to increase and more equitably distribute 
wealth, while decreasing energy consumption per unit of wealth created, or (more urgently), decreasing carbon dioxide emissions per unit of wealth created.

Given that many people live lives which involve friends, family, and business partners very far away, transport policy will have to look beyond the transport system proper, as a simple minded policy of carbon dioxide reduction will reduce the social capital of travellers and firms by encouraging them to give up existing contacts. Transport policy will have to identify ways in which travellers and firms can be supported in the reshuffling and rebuilding of their social capital. Putnam, Feldstein and Cohen (2006) outline some of these initiatives and approaches. Firms will need help to develop technologies that can benefit from increases in scale and scope without necessarily increasing market size. It will not be enough to rely on the growth of service-sector industries to decouple economic growth and energy consumption.

These larger questions have to be kept in mind, and while the immediate research questions are more modest in scope, they are ambitious in comparison to what has been undertaken so far. It is essential that the work undertaken for Switzerland is replicated elsewhere. While it seems reasonable to assume that other countries have shrunk as much as Switzerland, it is important to quantify this phenomenon. Given its importance, any new study should address the freight sector as well, and include the changes in freight costs, which have been dramatic (See for example Levinson 2006). The scale of analysis should be expanded as well, because many of these processes are now occurring fastest at the global scale. How much smaller has the world become for passengers and freight since 1950?

The social network analysis should also be replicated; ideally, new studies should be comparative, in order to avoid the trap of a national focus. It may be that the networks of farmers in India are as large or larger than those of farmers in the United States, as Indian farmers invest more heavily in the educational success of their children. Finally, there is the special challenge of tracing and reconstructing changes over time. New survey methods will be needed for the retrospective work, but also for the ongoing benchmarking, so as to make the process easier for the respondents.

\section{Acknowledgements}

The author gratefully acknowledges the access that Mr. Tschopp and Mr. Fröhlich, both IVT, ETH Zürich, have given me to the unpublished results of their doctoral research. Mr. Frei, IVT, ETH Zürich, has been in charge of the social network survey discussed above. The journal editors, Kevin Krizek and David Levinson, and the reviewers provided many fruitful suggestions and advice on the text and its content. 


\section{References}

Aschauer, D. 1989. Is public expenditure productive? Journal of Monetary Economics, 23 (2): 177-200.

Axhausen, K.W., C. Dolci, P. Fröhlich, M. Scherer, and A. Carosio 2008. Constructing time scaled maps: Switzerland 1950-2000. Transport Reviews, 28 (3): 391-413.

Axhausen, K.W., P. Fröhlich, and M. Tschopp [forthcoming]. Changes in Swiss accessibility since 1850, in H. Gunn ed., Economic Impact of Changing Accessibilities. Elsevier, Oxford.

Bonser, K.J. 1970. The drovers, who they were and how they went: An epic of the English countryside. Country Book Club, Newton Abbot.

Bundesamt für Raumentwicklung 2000. Mikrozensus zum Verkehrsverhalten 2000. http://www.are.admin.ch/imperia/md/content/are/gesamtverkehr/verkehrsforschung2/ 25.xls

Bureau of Transportation Statistics 1995. Nationwide Personal Transportation Survey 1995. http://www.transtats.bts.gov/DL_SelectFields.asp?Table_ID=1036\&DB_ Short_Name=NPTS.

Campbell, K.E. 1990. Networks past: A 1939 Bloomington neighbourhood. Social Forces, 69 (1): 139-155.

Campbell, K.E., and B.A. Lee 1992. Sources of personal neighbor networks: Social integration, need or time. Social Forces, 70 (4): 1077-1100.

Carrasco, J.A. 2006. Social activity-travel behaviour: A personal networks approach. Department of Civil Engineering, University of Toronto.

Christaller, W. 1933. Die zentralen Orte in Süddeutschland, reprint 1980. Wissenschaftliche Buchgesellschaft, Darmstadt.

Clark, G. 2007. Farewell to Alms: A Brief Economic History of the World. Princeton University Press.

Day, G. 2006. Community and Everyday Life. Routledge, London.

Fosgerau, M. 2005. Unit income elasticity of the value of travel time savings. Working paper, Danish Transport Research Institute, Copenhagen.

Frei, A. 2005. Was hätte man 1960 für einen Sharan bezahlt?. MSc Thesis, Department Bau, Umwelt und Geomatik, ETH Zürich, Zürich.

Fritzsche, B., T. Frey, U. Rey, and S. Romer 2001. Historischer Strukturatlas der Schweiz: Die Entstehung der modernen Schweiz, Verlag hier+jetzt, Baden.

Fröhlich, P. 2008. Änderungen der Intensitäten im Arbeitspendlerverkehr von 1970 bis 2000. dissertation, ETH Zürich.

Kesselring, H., P. Halbherr, and R. Maggi (1982). Strassennetzausbau und raumwirtschaftliche Entwicklung. Verlag Paul Haupt, Bern.

Levinson, M. 2006. The box: How the shipping container made the world smaller and the world economy bigger. Princeton University Press. 
Lloyd, P. 1984. Community action: Panacea or placebo. RAIN, 63 (8): 13-15.

Löchl, M., S. Schönfelder, R. Schlich, T. Buhl, P. Widmer, and K.W. Axhausen 2005. Untersuchung der Stabilität des Verkehrsverhaltens. Final report for SVI 2001/514, Schriftenreihe, 1120, Bundesamt für Strassen, UVEK, Bern.

McCormik, M. 2001. Origins of the European economy. Cambridge University Press. Mok, D., and B. Wellman 2007. Did distance matter before the Internet? Social Networks, 29 (3): 430-461.

Putnam, R.D., L.M. Feldstein, and D. Cohen 2003. Better together: Restoring the American community. Schuster and Schuster Paperbacks, New York.

Raff, D.M.G., and M. Trajtenberg 1995. Quality-adjusted prices for the American automobile industry: 1906-1940. Working paper 5032. National Bureau of Economic Research, Cambridge.

Ricardo, D. 1817. Principles of political economy and taxation. John Murray, London.

Rietveld, P., and F. Bruinsma 1998. Is transport infrastructure effective? Springer Verlag, Berlin.

Shirley, C., and C. Winston 2004. Firm inventory behavior and the returns from highway infrastructure investments. Journal of Urban Economics 55 (2): 398-415.

Smith, A. 1776. An inquiry into the nature and causes of the wealth of nations. 1999 reprint. Penguin, London.

Spufford, P. 2002. Power and profit: The merchant in medieval Europe. Thames and Hudson, New York.

Tschopp, M. 2007 Änderungen Verkehrsinfrastruktur und räumliche Entwicklung in der Schweiz 1950-2000. Dissertation. Universität Zürich.

Vries, J. de, and A. Van der Woude 1997. The first modern economy: Success, failure, and perseverance of the Dutch economy, 1500-1815. Cambridge University Press. 